\title{
ESTUDO COMPARATIVO DAS EMISSÕES EXAUSTIVAS CONVENCIONAIS E NÃO CONVENCIONAIS EM VEÍCULOS LEVES E MOTOCICLOS DE MÚLTIPLAS CILINDRADAS UTILIZANDO OS CICLOS FTP 75 [1] (VEÍCULO) E WMTC [2] (MOTOCICLOS).
}

\author{
Marcello Depieri ${ }^{1}$, Gino Montanari ${ }^{1}$, Raphael Sedano ${ }^{1}$ e Claudia R.S.Geraldi ${ }^{1}$ \\ ${ }^{1}$ Magneti Marelli Sistemas Automotivos \\ E-mails: marcello.depieri@magnetimarelli.com, \\ gino.montanari@magnetimarelli.com, \\ raphael.sedano@magnetimarelli.com, claudia.silva@magnetimarelli.com,
}

\section{RESUMO}

As emissões de gases poluentes provenientes dos veículos automotores à combustão interna tem uma contribuição significativa para a poluição atmosférica, principalmente nos centros urbanos, essa poluição gera efeitos nocivos à saúde pública e ao meio ambiente.

Para reduzir a poluição, os órgãos governamentais implementaram meios de controle destas emissões através de programas, no Brasil temos o PROCONVE [3] que definiu em suas várias fases os limites para a emissão dos poluentes em veículos 4 rodas, mais recentemente surgiu o PROMOT [4], este aplicado para o segmento de 2 rodas. Estes programas colocam o Brasil no mesmo nível dos países industrializados que possuem controle de emissões atmosféricas.

Estas medidas de controle definiram limites de emissão de poluentes de forma gradativa para veículos novos, e com o objetivo de atender estes limites, houve uma rápida evolução tecnológica na indústria de motos.

O presente trabalho tem como objetivo, comparar as emissões convencionais ( $\mathrm{CO}$, NOx e THC), conforme ABNT NBR 6601 [5] e não convencionais (Aldeídos) conforme ABNT NBR 12026 [6] dos veículos leves e motociclos de cilindradas variadas, ambos operando nos ciclos FTP 75 [1] e WMTC [2] .

A partir dos dados medidos no Laboratório de Emissões Veiculares, foi possível quantificar as emissões de veículos leves e motociclos, simulando as alterações de ciclos e os valores de emissões destas duas categorias, de acordo com os procedimentos de Homologação aplicadas nestes segmentos.

\section{INTRODUÇÃO}


Com a expansão da frota de veículos em circulação nos grandes centros urbanos nos últimos anos, surgiu a preocupação com o aumento da poluição atmosférica, e para minimizar os problemas decorrentes destas emissões, houve a necessidade da implementação de programas de controle de emissões.

Os programas PROCONVE [3] e PROMOT [4] vêm desempenhando um papel fundamental no controle das emissões atmosféricas no território brasileiro.

Para o segmento de 4 rodas estamos na fase L6 do PROCONVE [3], conforme resolução $\mathrm{N}^{\circ} 415$ [7], de 24 de setembro de 2009.

Em 13 de julho de 2011 foram estabelecidas as novas fases do PROMOT [4] chamado de PROMOT IV, através da Resolução $N^{\circ} 432$ [8], a tabela 1 demonstra os limites vigentes para o segmento de 4 e 2 rodas.

Tabela 1 Limites de Emissão para os segmentos de 2 e 4 rodas

\begin{tabular}{|c|c|c|c|c|c|}
\hline & \multicolumn{2}{|c|}{$\begin{array}{c}\begin{array}{c}\text { Motociclos e } \\
\text { Similares }\end{array} \\
\text { PROMOT [4] IV } \\
\text { fase 2 } \\
2016\end{array}$} & & \multicolumn{2}{|c|}{$\begin{array}{c}\text { Veículos Leves } \\
\text { e Comerciais } \\
\text { PROCONVE [3] } \\
\text { PL6 } \\
2014\end{array}$} \\
\hline & $\begin{array}{l}<130 \\
\mathrm{~km} / \mathrm{h}\end{array}$ & $\begin{array}{l}>=130 \\
\mathrm{~km} / \mathrm{h}\end{array}$ & & $\begin{array}{l}<1700 \\
\mathrm{~kg}\end{array}$ & $\begin{array}{c}>=1700 \\
\mathrm{~kg}\end{array}$ \\
\hline $\begin{array}{c}\mathrm{CO} \\
(\mathrm{g} / \mathrm{km})\end{array}$ & 2,00 & 2,00 & $\begin{array}{c}\mathrm{CO} \\
(\mathrm{g} / \mathrm{km})\end{array}$ & 1,30 & 2,00 \\
\hline $\begin{array}{c}\mathrm{HC} \\
(\mathrm{g} / \mathrm{km})\end{array}$ & 0,56 & 0,25 & $\begin{array}{l}\text { NMHC } \\
(\mathrm{g} / \mathrm{km})\end{array}$ & 0,05 & 0,06 \\
\hline $\begin{array}{c}\text { Nox } \\
(\mathbf{g} / \mathbf{k m}) \\
\end{array}$ & 0,13 & 0,17 & $\begin{array}{c}\text { NOx } \\
(\mathrm{g} / \mathrm{km}) \\
\end{array}$ & 0,08 & 0,25 \\
\hline $\begin{array}{l}\text { Aldeídos } \\
\text { (g/km) }\end{array}$ & --- & --- & $\begin{array}{c}\text { Aldeídos } \\
(\mathrm{g} / \mathrm{km})\end{array}$ & 0,02 & 0,03 \\
\hline $\begin{array}{c}\text { Evaporativas } \\
\text { (g) }\end{array}$ & 1,00 & 1,00 & $\begin{array}{l}\text { Evaporativas } \\
\text { (g) }\end{array}$ & 1,50 & 1,50 \\
\hline
\end{tabular}

Para determinação e quantificação das emissões, os veículos percorrem ciclos específicos conforme regulamentação. A figura 1 demonstra o ciclo de condução urbana, utilizado pelo segmento de 4 rodas, a figura 2 demonstra o ciclo de condução para o segmento de 2 rodas.

Este ciclo de motocicletas foi harmonizado recentemente e é utilizado na Europa, ambos os ciclos representam com fidelidade as formas de condução dos veículos e motociclos nos centros urbanos, possuem partida à frio, acelerações, desacelerações, trechos de velocidade estabilizada e períodos de marcha lenta. 


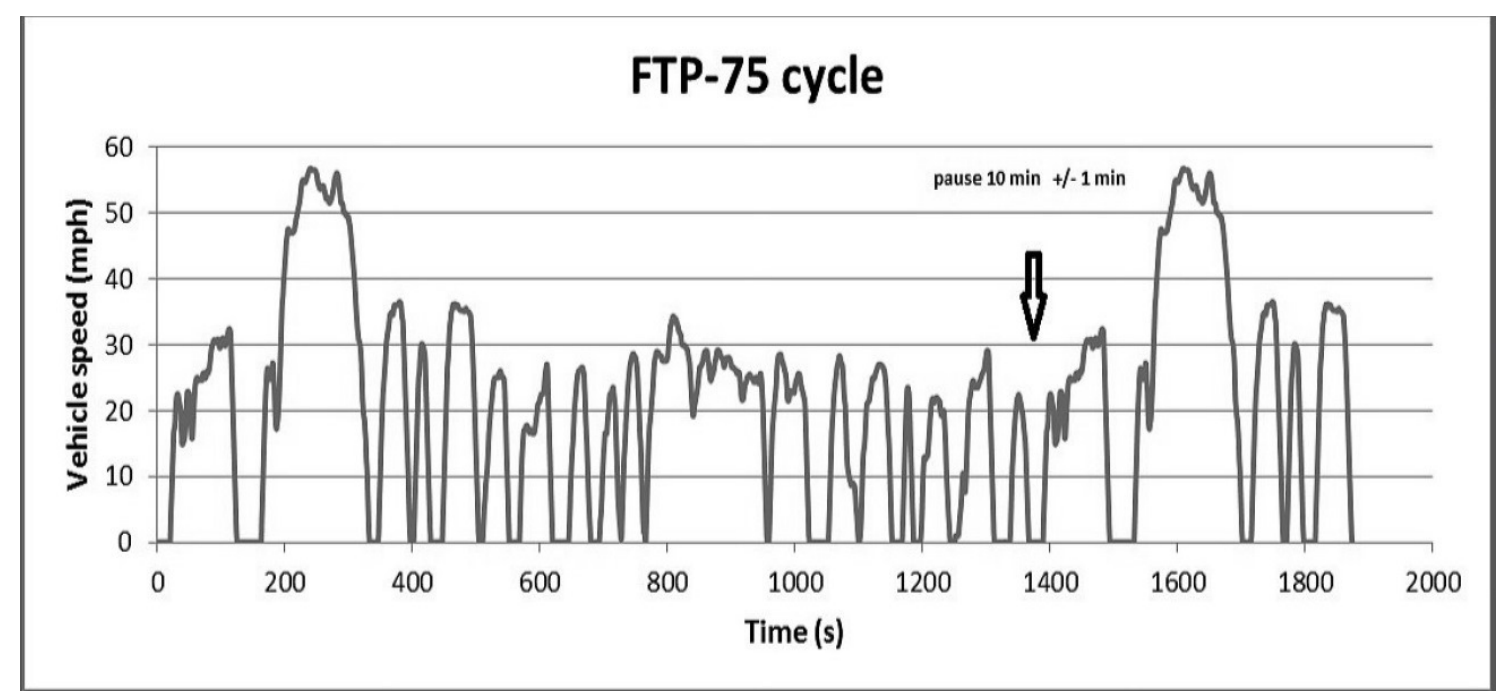

Figura 1 Ciclo de condução para veículos 4 rodas.

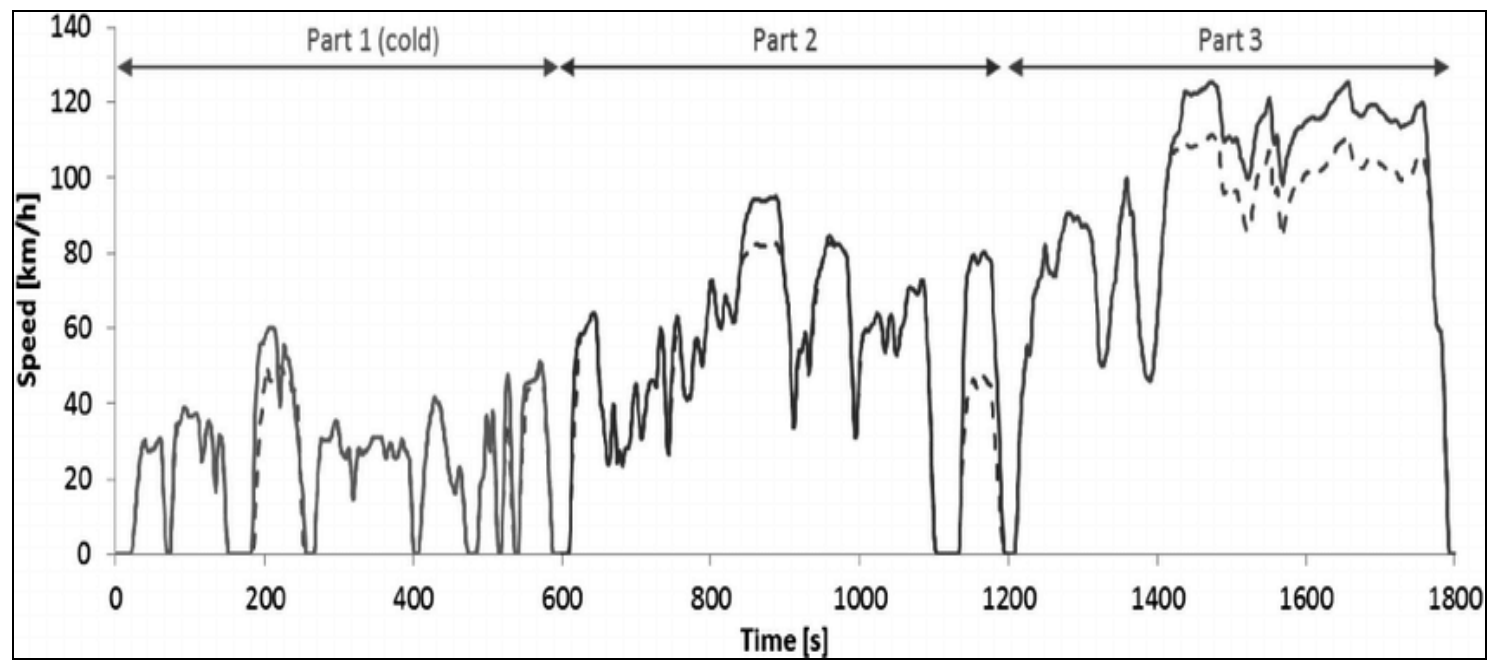

Figura 2 Ciclo de condução para veículos 2 rodas.

O ciclo de condução de veículos 4 rodas, permaneceu sem alterações ao longo das fases do programa de emissões, já o ciclo de condução de motociclos e similares foi alterado na sua fase IV, o novo ciclo do WMTC [2] conforme figura 2 é muito mais próximo da condução real praticada nos centros urbanos.

O ciclo para as motocicletas prevê algumas situações, onde algumas motos com menor cilindrada não consigam acompanhar o ciclo e permite velocidades menores, conforme linha pontilhada indicada na figura 2.

Para motocicletas de baixa cilindrada aplica-se a $1^{\circ}$ parte do WMTC [2] com velocidade reduzida, esta é reproduzida com partida à frio e repetida com o motociclo à quente, o ciclo tem duração de 1200 segundos conforme definido pelo PROMOT [4] IV. 
A partir dos dados medidos em Laboratório de Emissões, foi possível quantificar as emissões de veículos leves e motociclos, simulando as alterações de ciclos e os valores de emissões destas duas categorias, de acordo com os procedimentos de Homologação aplicadas para estes segmentos.

Este trabalho traz as respostas das questões dos meios de comunicação e fóruns técnicos, sobre a real situação das emissões destes dois seguimentos e desfaz vários mitos sobre este tema.

\section{METODOLOGIA}

Os ensaios foram realizados no Laboratório de Emissões Veiculares da Magneti Marelli. A figura 3 demonstra o esquema dos equipamentos do Laboratório de Emissões para o segmento de 2 e 4 rodas.
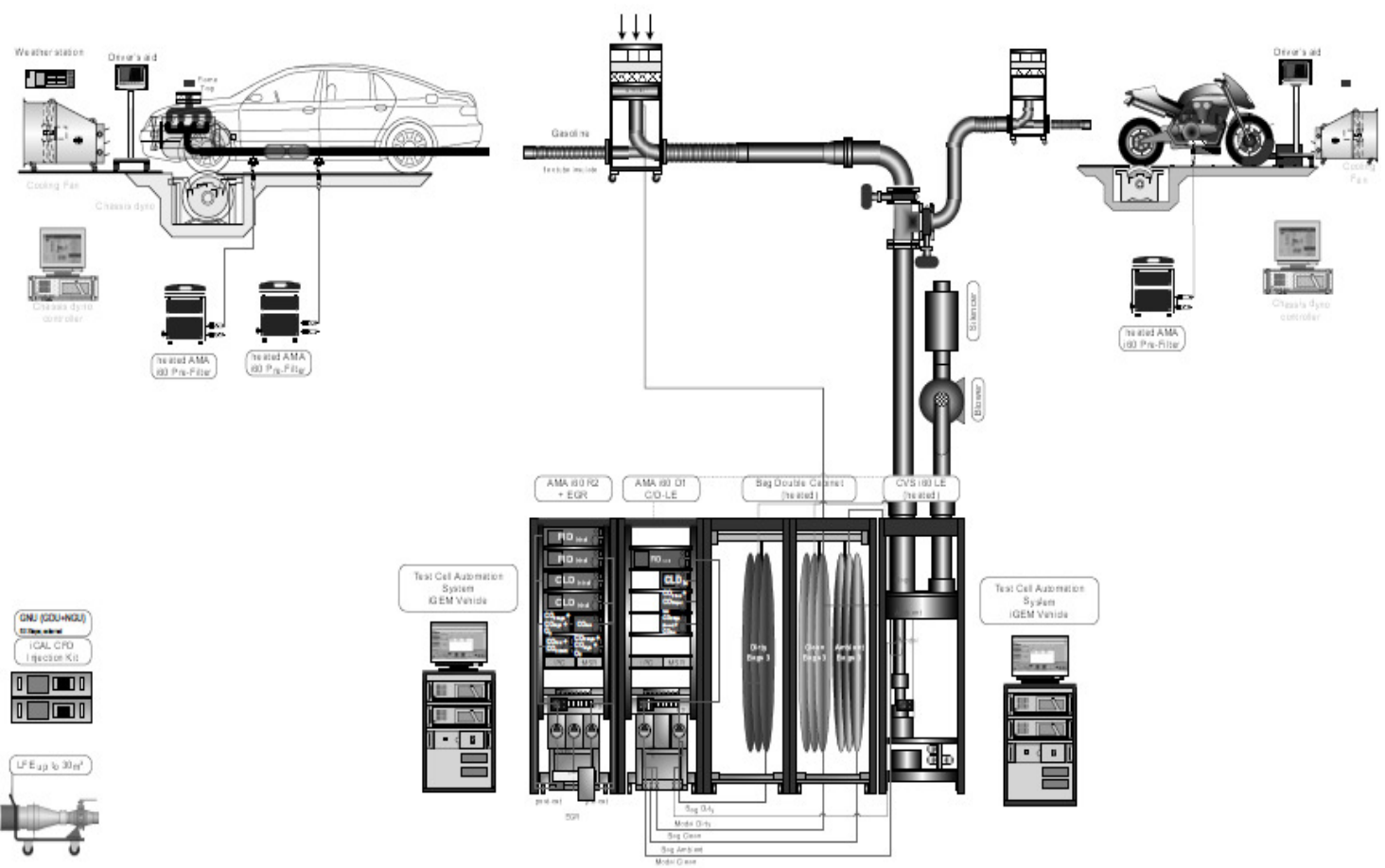

Figura 3 Equipamentos do Laboratório de Emissões

A figura 4 apresenta a fotografia dos recursos utilizados para a elaboração deste trabalho. 


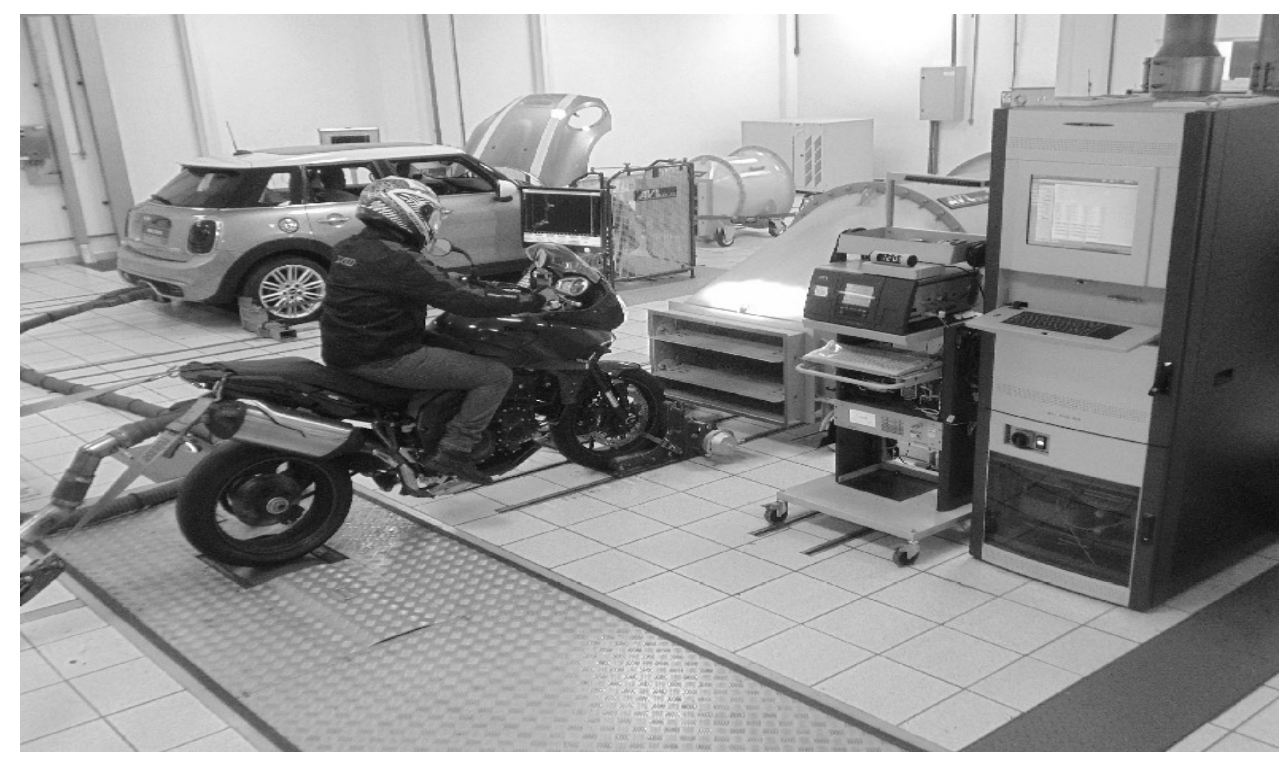

Figura 4 Laboratório de veículos e Motociclos

O Laboratório utilizado para estas medições compartilha o mesmo sistema de amostragem e bancada de analisadores, porém, possui dinamômetros específicos, sendo um dinamômetro de 48 " para veículos de 4 rodas e outro de $600 \mathrm{~mm}$ de diâmetro para o segmento de 2 rodas.

\section{RESULTADOS}

Foram medidos os valores de emissões em veículos de 2 e 4 rodas, de acordo com o processo de Homologação de cada segmento, e também alternando os ciclos de condução.

Desta forma, obtivemos os resultados dos veículos de 4 rodas nos ciclos de condução conforme PROCONVE [3] e PROMOT [4], assim como os resultados do seguimento de 2 rodas nos ciclos de condução conforme PROMOT [4] e PROCONVE [3].

\subsection{Limites legais de emissão de poluentes dos programas de controle}

Os limites legais dos programas não são semelhantes, para isto, foram calculados os valores medidos e apresentados em percentual do limite de cada segmento. Desta forma, foi possível fazer um comparativo dos resultados em relação ao limite de cada ciclo de condução.

Para o Limite de Hidrocarbonetos (THC) em veículos 4 rodas, adotou-se uma simulação considerando os valores sem a dedução do gás metano. Para a aplicação destes valores foram observados os resultados disponíveis no banco de dados do laboratório, onde a dedução média de Metano $(\mathrm{CH} 4)$ é em torno de 26,4\% nas medições de Hidrocarbonetos (THC) para a determinação do Não Metano Hidrocarbonetos (NMHC), que atualmente é controlado para veículos leves. 
Para estimar um valor de limite de Hidrocarbonetos (THC) para veículos leves, acrescentou-se um percentual de aproximadamente $26,4 \%$ sobre 0 limite de Não Metano Hidrocarbonetos (NMHC), a fim de tornar possível esta comparação com o segmento de 2 rodas, pois este segmento não possui esta dedução de metano, portanto, o limite estimado de THC na apresentação de resultados estará na mesma base e será considerado conforme tabela 2.

Tabela 2 Tabela com limites de Hidrocarbonetos (THC)

\begin{tabular}{|c|c|c|c|c|c|}
\hline & \multicolumn{2}{|c|}{ Motociclos e Similares } & & \multicolumn{2}{|c|}{ Veículos Leves e Comerciais } \\
\hline & \multicolumn{2}{|c|}{$\begin{array}{c}\text { PROMOT IV fase } 2 \\
2016\end{array}$} & & \multicolumn{2}{|c|}{\begin{tabular}{|c|} 
PROCONVE PL6 \\
2014
\end{tabular}} \\
\hline & $<130 \mathrm{~km} / \mathrm{h}$ & $\geq 130 \mathrm{~km} / \mathrm{h}$ & & $<1700 \mathrm{~kg}$ & $\geq 1700 \mathrm{~kg}$ \\
\hline \multirow{2}{*}{ THC $(\mathrm{g} / \mathrm{km})$} & \multirow{2}{*}{0,56} & \multirow{2}{*}{0,25} & NMHC $(\mathrm{g})$ & & \\
\hline & & & THC estimado $(\mathrm{g} / \mathrm{km})$ & 0,07 & 0,082 \\
\hline
\end{tabular}

Para a emissão de Aldeído Total (HCO), foi adotado o mesmo valor para ambos os segmentos, hoje este limite é de $0,020 \mathrm{~g} / \mathrm{km}$ e aplicado somente para os veículos 4 rodas.

Todos os veículos e motocicletas foram abastecidos com gasolina padrão com $22 \%$ de etanol anidro emissões (EAR).

\subsection{Resultados obtidos com o ciclo de emissões de veículos 4 rodas (FTP 75 [1])}

Conforme representado na figura 5, temos os resultados de emissões dos ensaios com veículos 4 rodas e motocicletas de alta cilindrada. 


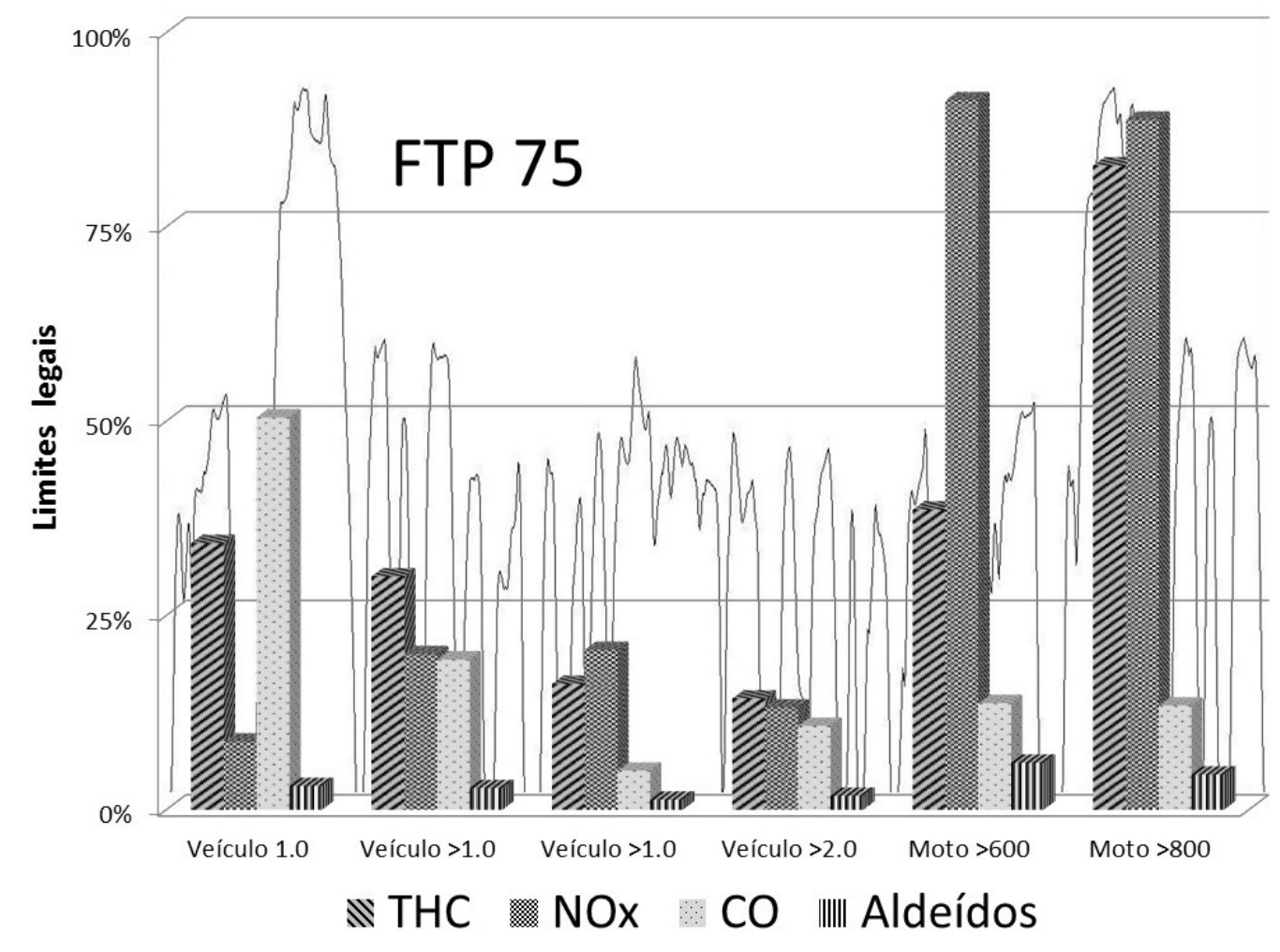

Figura 5 Resultados ciclo FTP 75 [1]

Os veículos de 4 rodas apresentaram resultados abaixo dos 50\% do limite legal.

As motocicletas acompanharam sem dificuldade o ciclo de veículos leves e tiveram resultados dentro dos limites do PROCONVE [3] L6. Os valores de Óxidos de Nitrogênio (NOx) ficaram próximo do limite legal e a motocicleta acima de $800 \mathrm{cc}$ apresentou um valor de emissão de Hidrocarbonetos (THC) elevado.

Embora não seja controlada a emissão de Aldeído Total (HCO) pelo PROMOT [4], as motocicletas apresentaram valores dentro do limite adotado, porém acima do segmento de 4 rodas.

$\mathrm{Na}$ figura 6, temos os resultados dos ensaios de veículos e motocicletas de baixa cilindrada. 


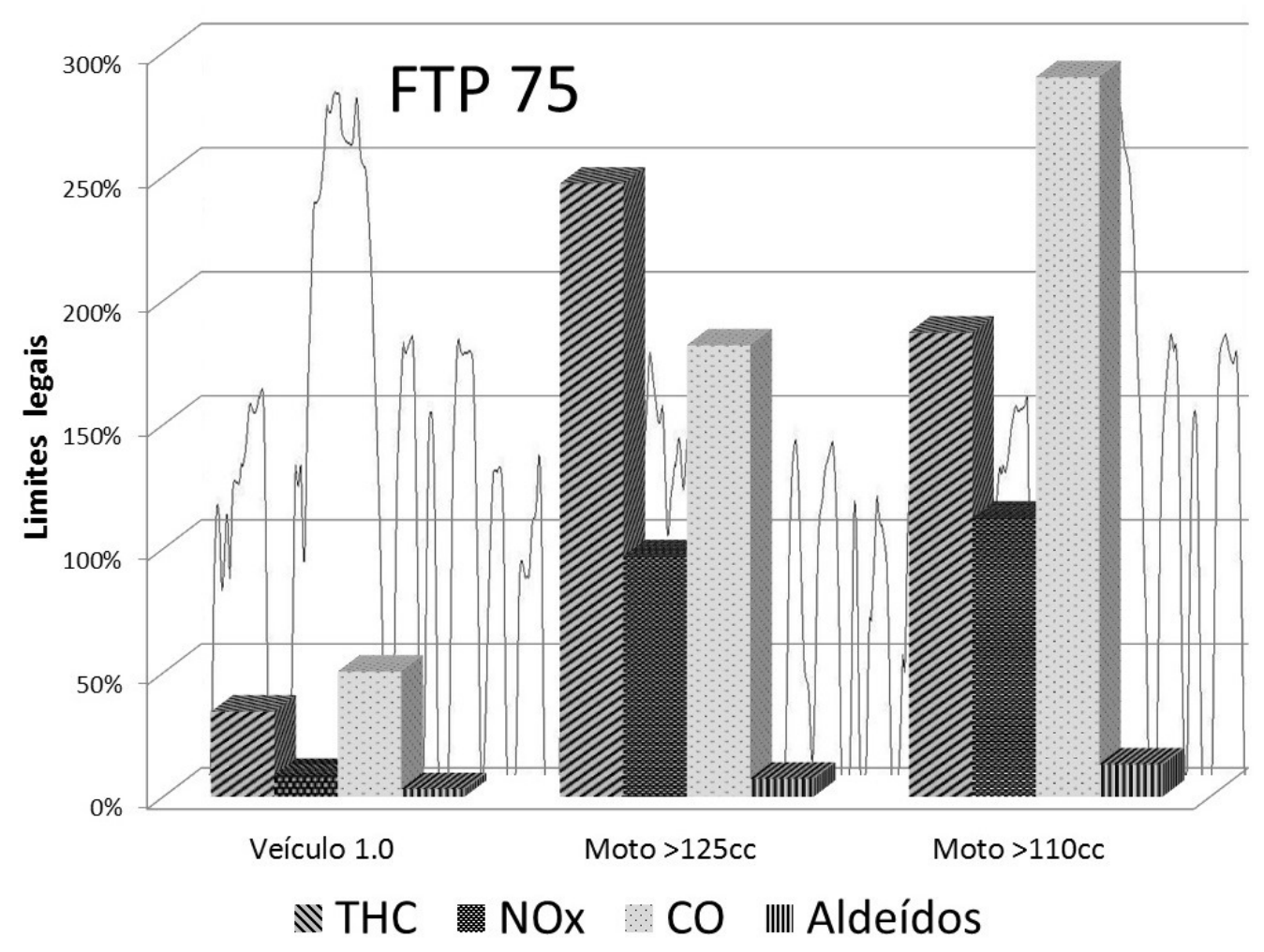

Figura 6 Resultados ciclo FTP 75 [1]

Os veículos de 4 rodas apresentaram resultados inferiores a $50 \%$ do limite estabelecido pelo PROCONVE [3] L6.

As motocicletas de baixa cilindradas tiveram dificuldades para percorrer o ciclo de veículos leves. As emissões apresentaram valores elevados de Hidrocarbonetos e Monóxido de carbono (THC/CO), excedendo os limites do programa aplicado ao segmento de 4 rodas, já as emissões de Óxidos de Nitrogênio (NOx) ficaram próximos deste limite. Os resultados de Aldeídos Totais (HCO) apresentaram resultados muito abaixo limite adotado.

\subsection{Resultados obtidos com o ciclo de emissões de veículos 2 rodas (WMTC [2])}

Conforme representado na figura 7 , temos os resultados dos ensaios de veículos 4 rodas e motocicletas de alta cilindrada realizados com o ciclo de condução do segmento de 2 rodas. 


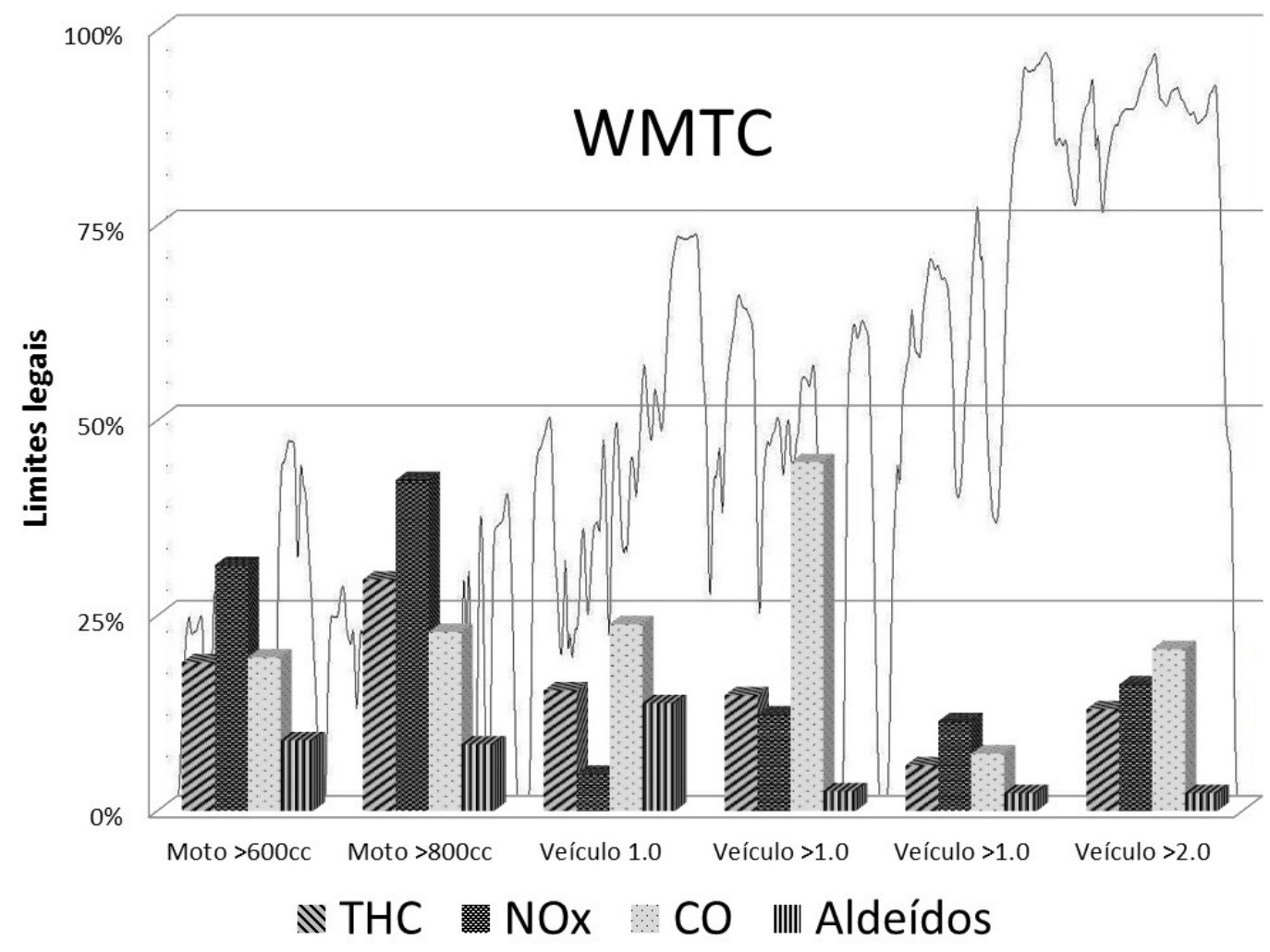

Figura 7 Resultados ciclo WMTC [2]

Os valores de emissões convencionais das motocicletas apresentaram resultados inferiores ao limite do programa PROMOT [4]. Os resultados de Aldeídos Totais (HCO) ficaram abaixo do limite adotado (PROCONVE [3]), porém mostrou-se acima das emissões dos veículos de 4 rodas.

Os veículos de 4 rodas de baixa cilindrada tiveram dificuldades para acompanhar o ciclo deste segmento, porém todos os poluentes ficaram abaixo dos limites do programa.

\subsection{Resultados obtidos de acordo com o ciclo de emissões de veículos 2 rodas (WMTC [2]) para baixa cilindrada}

Este ciclo é aplicado para motocicletas com motor abaixo de 150 cilindradas e cuja velocidade máxima não ultrapasse $100 \mathrm{~km} / \mathrm{h}$, neste caso foi utilizado um veículo de 4 rodas de 1,0L e duas motocicletas para comparação dos resultados, representados no gráfico conforme figura 8 . 


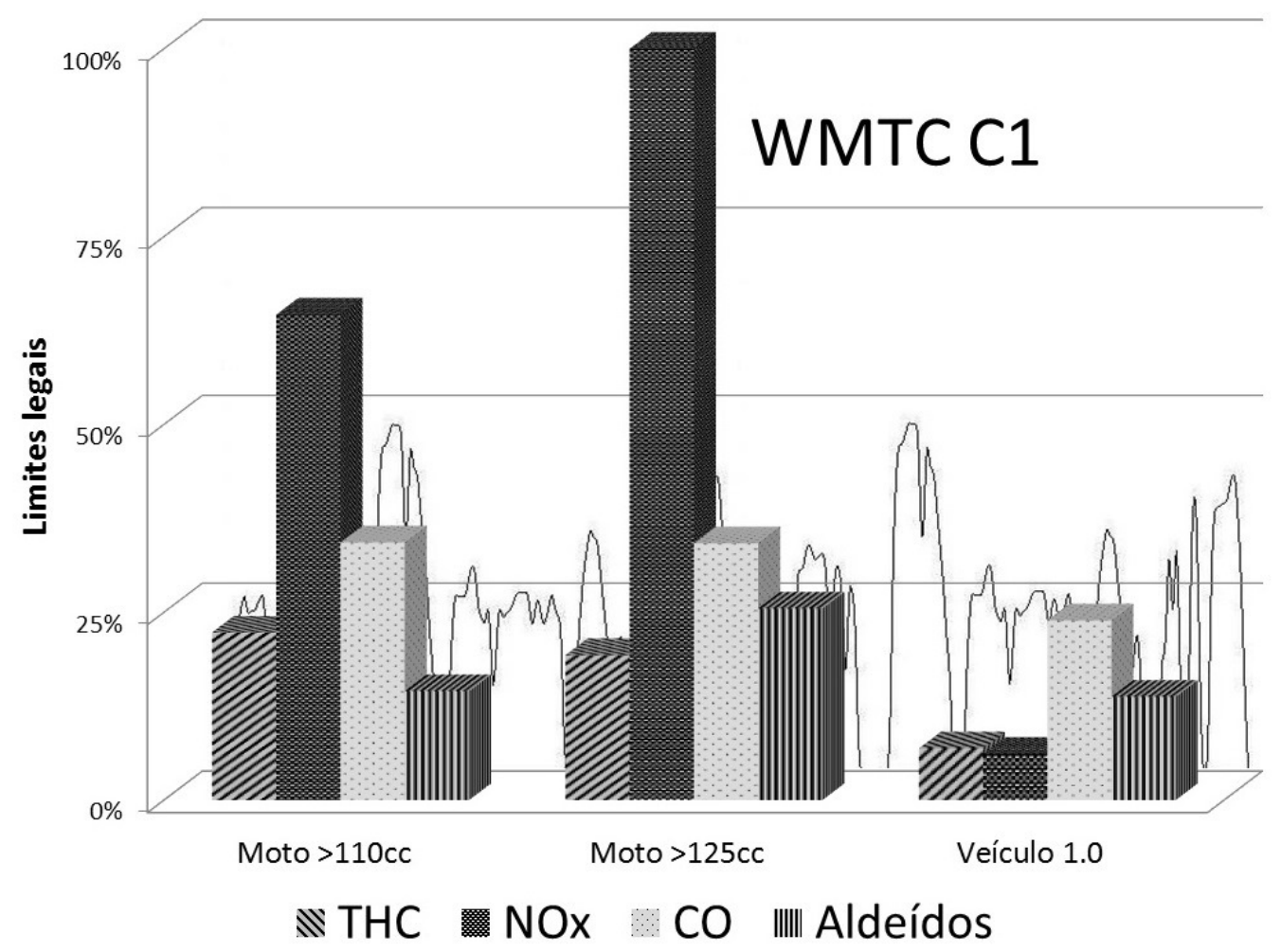

Figura 8 Resultados ciclo WMTC [2] C1

Neste ciclo de condução as motocicletas apresentaram resultados de emissões de Óxidos de Nitrogênio (NOx) próximos ao limite aplicado para esta categoria.

As emissões do veículo de 4 rodas permaneceu com valores de emissões muito baixos em relação aos limites deste segmento de 2 rodas.

\section{CONCLUSÃO}

O objetivo principal foi comparar as emissões de diferentes veículos em diferentes ciclos de condução, para determinar o real comportamento da emissão dos poluentes nos centros urbanos e trazer às respostas dos fóruns técnicos para as questões das emissões destes seguimentos.

Neste trabalho foi possível reproduzir estes ensaios, permitindo quantificar estas emissões e também identificar possíveis melhorias no desempenho do motor, no caso das motocicletas de baixa cilindrada.

A maioria dos resultados encontrados em ambos os ciclos e categorias, atendem os limites estabelecidos pelas legislações vigentes. Em todas as simulações notamos uma emissão de poluentes dos veículos 4 rodas sempre inferiores aos obtidos pelo segmento de 2 rodas. 
As motos de cilindradas acima de $600 \mathrm{~cm}^{3}$, percorreram com facilidade o ciclo de condução aplicado para veículos 4 rodas.

As motocicletas de baixa cilindradas acompanharam com dificuldade alguns trechos deste ciclo que atinge a velocidade de $90 \mathrm{~km} / \mathrm{h}$, vale ressaltar que, o ciclo estipulado para essas motos (WMTC C1) não ultrapassa a velocidade de $50 \mathrm{~km} / \mathrm{h}$, portanto é coerente compreender tal comportamento.

Os veículos 4 rodas apresentaram dificuldade para acompanhar as acelerações do ciclo WMTC [2], exceção para os motores de maior cilindrada.

Com relação à eficiência, os veículos 4 rodas se mostraram mais eficientes, pois emitem uma quantidade menor de poluentes mesmo com um peso muito maior e capacidade para transportar mais passageiros.

O controle da emissão de Aldeído Total (HCO) em motociclos não é controlado na legislação atual, mas foi possível quantificar a emissão deste poluente. Aplicando os limites existentes no PROCONVE [3], as emissões nas motocicletas apresentaram valores inferiores aos limites adotados, favorecidos pela utilização da gasolina A22, isto também é percebido nas emissões dos veículos leves.

No geral, embora os limites máximos de emissão definidos nas legislações sejam diferentes, observamos que existe um alinhamento em relação às emissões em ambos os segmentos, com exceção das motocicletas de baixa cilindradas, que apresentaram valores de emissões muito acima dos limites legais no ciclo de condução para veículos 4 rodas, porém esta melhoria se dará, quando o segmento substituir o sistema de alimentação do motor por alternativas com mais recursos de controle, como a injeção eletrônica.

\section{AGRADECIMENTOS}

A Magneti Marelli e a equipe do laboratório de emissões.

\section{REFERÊNCIAS}

[1] FTP 75, método de determinação de emissões para veículos 4 rodas, conforme ABNT NBR 6601.

[2] WMTC, ECE/TRANS/180/Add.2, World Motorcycle Test Cycle.

[3] MINISTÉRIO DO MEIO AMBIENTE. Resolução CONAMA n`18, Programa de Controle da Poluição do Ar por Veículos Automotores PROCONVE [3], 1986.

[4] MINISTÉRIO DO MEIO AMBIENTE. Resolução CONAMA no 297.

Estabelecimento dos limites para emissão de gases poluentes por ciclomotores, motociclos e veículos similares novos PROMOT [4] , 2002.

[5] ABNT. NBR 6601: Determinação de hidrocarbonetos, monóxido de carbono, óxidos de nitrogênio, dióxido de carbono e material particulado no gás de escapamento, 2012. 
[6] ABNT. NBR 12026: Determinação de aldeídos e cetonas contidas no gás de escapamento, por cromatografia líquida, 2009.

[7] MINISTÉRIO DO MEIO AMBIENTE. Resolução CONAMA no 415, de 24 de setembro de 2009.

[8] MINISTÉRIO DO MEIO AMBIENTE. Resolução CONAMA no 432.

Estabelece novas fases de controle de emissões de gases poluentes por ciclomotores, motociclos e veículos similares novos e dá outras providências, em observância a resolução n²97, 2011. 